\title{
Efeitos in vitro de ocratoxina A, deoxinivalenol e zearalenona sobre a viabilidade celular e atividade de E-ADA em linfócitos de frangos de corte ${ }^{1}$
}

\author{
Claudia Lautert ${ }^{2}$, Laerte Ferreiro ${ }^{2}$, Carine E.P. Zimmermann ${ }^{3}$, Lívia G. Castilhos ${ }^{4}$, Francielli \\ P.K. de Jesus ${ }^{2}$, Régis A. Zanette ${ }^{3}$, Daniela B.R. Leal ${ }^{4}$ e Janio M. Santurio ${ }^{3 *}$
}

\begin{abstract}
Lautert C., Ferreiro L., Zimmermann C.E.P., Castilhos L.G., Jesus F.P.K., Zanette R.A., Leal D.B.R. \& Santurio J.M. 2014. [In vitro effects of ochratoxin A, deoxynivalenol and zearalenone on cell viability and E-ADA activity in broiler chickens lymphocytes.] Efeitos in vitro de ocratoxina A, deoxinivalenol e zearalenona sobre a viabilidade celular e atividade de E-ADA em linfócitos de frangos de corte. Pesquisa Veterinária Brasileira 34(12):1173-1180. Setor de Micologia, Faculdade de Veterinária, Universidade Federal do Rio Grande do Sul, Av. Bento Gonçalves 9090, Porto Alegre, RS 91540-000, Brazil. E-mail: claudialautert@yahoo.com.br

Mycotoxins are a group of chemically diverse naturally occurring substances resulting from the secondary metabolism of pathogenic filamentous fungi. They are produced mainly by the genera Fusarium, Alternaria, Aspergillus and Penicillium which can contaminate grains and cereals such as wheat, corn and soy. According to the nature and the concentration levels, mycotoxins can induce toxic effects in food-production animals and humans. An in vitro study was conducted to evaluate the susceptibility of broiler chickens lymphocytes to different concentrations of ochratoxin A, deoxynivalenol and zearalenone. Each toxin was added to the cell medium at different concentrations $(0.001,0.01,0.1$ and $1 \mu \mathrm{g} / \mathrm{mL})$. Cell viability and ecto-adenosine deaminase activity were assessed at 24,48 and 72 hours by colorimetric assays. Thus, it were used $0.7 \times 10^{5}$ lymphocytes/mL in RPMI 1640 medium, supplemented with $10 \%$ fetal bovine serum and $2.5 \mathrm{IU}$ of penicillin/streptomycin per $\mathrm{mL}$, incubated at $37^{\circ} \mathrm{C}$ in a $5 \% \mathrm{CO}_{2}$ atmosphere. All the experiments were carried out in triplicate and the results were expressed as mean \pm standard error of the mean. The results showed that OTA and DON induced lymphocyte proliferation and reduced enzymatic activity in vitro $(\mathrm{P}<0,05)$, whereas ZEA also promoted proliferation $(\mathrm{P}<0,05)$, but neither alteration on enzymatic activity $(\mathrm{P}>0,05)$. It was possible to correlate the results about viability cell and ecto-adenosine deaminase activity, suggesting that, at minimal concentrations, the evaluated mycotoxins do not stimulated the enzymatic activity, which has proinflammatory action and contributes for the immunosuppression process, thus, avoiding a decrease on the viability cell. This is the first in vitro study conducted with OTA, DON and ZON in broiler chickens lymphocytes evaluating these parameters.
\end{abstract}

INDEX TERMS: Mycotoxins, leukocytes, cytotoxicity, poultry, colorimetric assays.

\footnotetext{
${ }^{1}$ Recebido em 13 de março de 2014.

Aceito para publicação em 10 de outubro de 2014.

${ }^{2}$ Setor de Micologia, Faculdade de Veterinária, Universidade Federal do Rio Grande do Sul (UFRGS), Av. Bento Gonçalves 9090, Porto Alegre, RS 95320-000, Brasil. E-mail: laerte.ferreiro@ufrgs.br

${ }^{3}$ Laboratório de Pesquisas Micológicas (LAPEMI), Departamento de Microbiologia e Parasitologia, Universidade Federal de Santa Maria (UFSM), Av. Roraima 1000, Santa Maria, RS 97105-900, Brasil. *Autor para correspondência: janio.santurio@gmail.com

${ }^{4}$ Laboratório de Microbiologia e Parasitologia (LAMIP), Departamento de Microbiologia e Parasitologia, UFSM, Av. Roraima 1000, Santa Maria, RS. E-mail: dbitencourtrosaleal@gmail.com
}

RESUMO.- Micotoxinas representam um vasto grupo de contaminantes químicos naturais originados a partir do metabolismo secundário de fungos filamentosos patogênicos. Elas são produzidas, principalmente, pelos gêneros Fusarium, Alternaria, Aspergillus e Penicillium, os quais podem contaminar grãos e cereais, como trigo, milho e soja. Conforme sua natureza e níveis de concentração, micotoxinas podem induzir efeitos tóxicos em animais de produção e humanos. Um estudo in vitro foi realizado para avaliar a susceptibilidade das células linfocitárias de frangos de corte a diferentes concentrações de ocratoxina A, deoxini- 
valenol e zearalenona. Cada micotoxina foi adicionada ao meio celular em diferentes concentrações $(0,001 ; 0,01 ; 0,1$ e $1 \mu \mathrm{g} / \mathrm{mL}$ ). A viabilidade celular e atividade de ecto-adenosina desaminase foram analisadas em 24, 48 e 72 horas através de ensaios colorimétricos. Para isso, foram utilizados $0,7 \times 10^{5}$ linfócitos/mL em meio RPMI 1640, suplementado com $10 \%$ de soro fetal bovino e 2,5 UI de penicilina/ estreptomicina por $\mathrm{mL}$, incubados em atmosfera de $5 \%$ de $\mathrm{CO}_{2}$ a $37^{\circ} \mathrm{C}$. Todos os experimentos foram realizados em triplicata e os resultados foram expressos como média e erro padrão da média. Os resultados obtidos demonstraram que tanto ocratoxina A como deoxinivalenol induziram proliferação linfocitária e baixa atividade enzimática in vitro $(P<0,05)$, enquanto zearalenona também induziu proliferação $(P<0,05)$, mas nenhuma alteração na atividade enzimática $(P>0,05)$. Foi possível correlacionar os dados referentes à viabilidade celular e atividade de ecto-adenosina desaminase, sugerindo que, em concentrações mínimas, as micotoxinas testadas não estimularam a atividade da enzima, que possui ação pró-inflamatória e contribui para o processo de imunossupressão e, portanto, evitando um decréscimo na viabilidade celular. Este é o primeiro estudo feito com OCRA, DON e ZEA sobre linfócitos de frangos de corte em cultivos in vitro na avaliação desses parâmetros.

TERMOS DE INDEXAÇÃO: Micotoxinas, leucócitos, citotoxicidade, aves domésticas, ensaios colorimétricos.

\section{INTRODUÇÃO}

Há muitos séculos se conhece a toxicidade de certos fungos. Entretanto, somente em 1.850, ao relacionar a ingestão de centeio infectado pelo fungo Claviceps purpurea com as características clínicas do ergotismo, foi levantada a possibilidade de haver risco à saúde humana e animal pela ingestão de metabólitos secundários produzidos por fungos (Santurio 2000). Micotoxinas são metabólitos fúngicos secundários contaminantes de uma série de grãos e frutas pré ou pós-colheita. Aflatoxinas, deoxinivalenol, ocratoxina A, fumonisinas, zearalenona, patulina e toxina T-2 são as mais importantes micotoxinas, as quais são caracteristicamente estáveis em condições ambientais e causadoras de diversos efeitos tóxicos em animais de laboratório, de produção e em humanos (Chen et al. 2008).

Ocratoxina A (OCRA) é uma micotoxina de ocorrência natural produzida por fungos do gênero Aspergillus e $\mathrm{Pe}$ nicillium em uma variedade de regiões geográficas e climáticas. Por ser um contaminante natural de alimentos estocados, e consequentemente, destinados à produção de animais como frangos, são relatados muitos surtos de ocratoxicose (Wang et al. 2009). As toxinas provenientes do gênero Fusarium, deoxinivalenol (DON) e zearalenona (ZEA), são as principais em humanos e na nutrição animal devido sua frequência e ocorrência concomitante em concentrações toxicologicamente relevantes em grãos de cereais no mundo inteiro (Goyarts et al. 2007).

Sistemas in vitro permitem tanto uma dosagem mais exata de toxinas, quanto uma duração de exposição definida em um meio quimicamente e fisicamente uniforme, se comparados a técnicas in vivo. Além disso, ensaios in vitro podem proporcionar resultados e conclusões significativos, reconhecidos e reproduzíveis. Várias linhagens celulares já foram utilizadas em estudos de culturas de tecidos para testes de citotoxicidade de diversas micotoxinas. Efeitos citotóxicos de células em cultura podem ser avaliados através do ensaio de MTT (3-(4,5-dimetiltiazol-2yl)-2,5-difenil brometo de tetrazolina). MTT é um reagente salino de coloração amarela que é reduzido a cristais púrpuros escuros de formazan pela ação de enzimas mitocondriais em células viáveis, sendo frequentemente utilizado em estudos de citotoxicidade de micotoxinas, para avaliação da viabilidade e proliferação celular (Lewis et al. 1999).

Alterações na integridade da membrana plasmática podem ser determinadas pela mensuração de enzimas liberadas no meio de cultura pelas células danificadas (Widestrand et al. 1999). Ecto-adenosina desaminase (E-ADA) é considerada uma enzima chave no metabolismo de purinas, catalisando a irreversível desaminação da adenosina e desoxiadenosina em inosina e desoxiinosina, respectivamente, e regulando as concentrações de adenosina (Ado) extracelular (Franco et al. 1997). E-ADA está presente em todos os tipos celulares, com alta atividade no timo, tecidos linfóides e linfócitos periféricos, desempenhando função essencial para o crescimento normal, diferenciação e proliferação de linfócitos T (Franco et al. 1997, Codero et al. 2001).

O escopo do presente trabalho de pesquisa visou avaliar os possíveis efeitos das micotoxinas OCRA, DON e ZEA, relacionados à viabilidade celular e atividade enzimática de E-ADA, em linfócitos de frangos de corte cultivados in vitro.

\section{MATERIAL E MÉTODOS}

Micotoxinas. As micotoxinas utilizadas foram ocratoxina A (OCRA), deoxynivalenol (DON) e zearalenona (ZEA) (Sigma Chemical Co., St. Louis, MO, USA). Elas foram solubilizadas em etanol (5\%), diluídas nas concentrações 0,$001 ; 0,01 ; 0,1$ e $1 \mu \mathrm{g} / \mathrm{mL}$ e adicionadas em cultivos celulares de linfócitos para respectiva avaliação.

Células e cultura. 0 experimento foi conduzido no Laboratório de Pesquisas Micológicas (LAPEMI-UFSM). Os linfócitos foram isolados do sangue de frangos de corte, respeitando a conduta do bem estar animal conforme Comissão de Ética em Uso Animal da Universidade Federal de Santa Maria (CEUA-UFSM). 0 pool sanguíneo foi coletado, de 30 aves comerciais da linhagem COBB 500 com 45 dias, através de tubos cônicos falcon com EDTA $10 \%$, e a técnica de separação celular utilizada, através de centrifugação por gradiente de densidade, conforme a descrita por Böyum (1968). Após contagem em câmara de Neubauer com adição do corante Azul de Trypan (0,1\%), foram utilizados $0,7 \times 10^{5}$ linfócitos/mL em meio RPMI 1640 (Sigma), suplementado com $10 \%$ de soro fetal bovino e 2,5 UI de penicilina/estreptomicina (Sigma), em estufa com atmosfera de $5 \%$ de $\mathrm{CO}_{2}$ a $37^{\circ} \mathrm{C}$. A suspensão de células foi colocada em placa de 96 micropoços e mantida em crescimento exponencial, em uma confluência de $80 \%$. Cada micotoxina foi adicionada $(20 \mu \mathrm{L})$ ao meio celular em diferentes concentrações $(0,001 ; 0,01 ; 0,1$ e $1 \mu \mathrm{g} / \mathrm{mL})$, exceto no grupo controle (0), contendo apenas meio de cultura e células. A viabilidade celular e a atividade enzimática de E-ADA foram analisadas em 24, 48 e 72 horas.

Ensaio de viabilidade celular. A viabilidade celular dos linfócitos de frangos de corte foi avaliada pelo ensaio de MTT (Vy- 
brant ${ }^{\circledR}$ MTT Cell Proliferation Assay Kit-Invitrogen). A reação é catalisada pela succinil desidrogenase mitocondrial e exige $\mathrm{NADH}$, que deve ser fornecida pelas células, proporcionando então uma indicação de competência mitocondrial ou respiratória. Cada poço, contendo os diferentes grupos representados pelas diferentes concentrações e micotoxinas testadas, foi inoculado com $10 \mu \mathrm{L}$ de MTT $(5 \mathrm{mg} / \mathrm{mL})$, e as células foram incubadas durante 4 horas em estufa com atmosfera de $5 \%$ de $\mathrm{CO}_{2}$ a $37^{\circ} \mathrm{C}$. Após, o meio foi cuidadosamente removido e o produto corado foi dissolvido com $50 \mu \mathrm{L}$ de DMSO (dimetilsulfóxido), realizando novamente incubação pelo período de $10 \mathrm{~min}$ sob as mesmas condições referidas acima. A leitura foi feita através de espectrofotometria (Bio-Rad model 3550 Microplate reader), utilizando um comprimento de onda de $595 \mathrm{~nm}$. Poços controles foram utilizados para verificar se houve ou não proliferação celular, e se a viabilidade foi influenciada pelas concentrações mínimas das respectivas micotoxinas. Os resultados foram expressos em porcentagem.

Determinação da atividade de E-ADA. E-ADA, em amostras de linfócitos, foi determinada espectrofotometricamente de acordo com o método colorimétrico de Giusti \& Galanti (1984), no qual $25 \mu \mathrm{L}$ de linfócitos reagem com adenosina (21mmol/L), $\mathrm{pH}$ 6,5 , em um período de incubação de 60 minutos a $37^{\circ} \mathrm{C}$. Este método é baseado na produção direta de amônia quando a adenosina desaminase tem sua ação na adenosina. 0 comprimento de onda utilizado para a leitura foi $620 \mathrm{~nm}$. Os resultados foram expressos em $U / m g$, na qual uma unidade (1U) de ADA é definida como a quantidade de enzima necessária para liberar $1 \mathrm{mmol}$ de amônia por minuto a partir da adenosina em condições padrão de ensaio.

Determinação protéica. A determinação de proteína foi realizada pelo método Azul de Comassie, usando albumina bovina como padrão, conforme descrito por Bradford (1976).

Análise estatística. A análise estatística foi realizada através do teste não paramétrico ANOVA de uma via seguido pelo post test Newman-Keuls, utilizando nível de significância de $\mathrm{P}<0,05$. Os experimentos foram realizados em triplicata e os resultados foram expressos como média e erro padrão da média.

\section{RESULTADOS}

Na avaliação da viabilidade celular, dos linfócitos de frangos de corte incubados com a micotoxina OCRA, observou-se proliferação celular $(111,20 \pm 4,90)$ no período de $48 \mathrm{~h}$ relacionada à menor concentração utilizada, $0,001 \mu \mathrm{g} / \mathrm{mL}$, em relação a 97,66 $\pm 1,33$ do grupo controle; enquanto que em $72 \mathrm{~h}$ de incubação, apenas a concentração de $0,1 \mu \mathrm{g} / \mathrm{mL}$ não influenciou resultado significativo, já que as demais concentrações: 0,$001 ; 0,01$ e $1 \mu \mathrm{g} / \mathrm{mL}$, também causaram comportamento proliferativo caracterizado pelos seguintes valores (média \pm erro padrão da média), respectivamente, $95,05 \pm 1,30 ; 100,25 \pm 1,11$ e $97,46 \pm 1,67$, quando comparadas ao grupo controle $(88 \pm 0,57)(\mathrm{P}<0,05)$ (Fig.1).

A micotoxina DON, na concentração de $0,01 \mu \mathrm{g} / \mathrm{mL}$, no período de $48 \mathrm{~h}$, induziu proliferação celular $(114,75 \pm 5,75)$ quando comparada ao grupo controle $(97,66 \pm 1,33$ ) (Fig.2) $(\mathrm{P}<0,05)$.

Quanto ao comportamento celular observado após a incubação com ZEA, evidenciou-se proliferação linfocitária nas amostras incubadas com as respectivas concentrações da micotoxina: 0,001 $(107,84 \pm 1,84) ; 0,01(105,97 \pm 2,02)$ e $0,1 \mu \mathrm{g} / \mathrm{mL}(105,97 \pm 1,12)$, somente no período de $48 \mathrm{~h}$, enquanto o grupo controle (o) apresentou $96,33 \pm 1,33$ de viabilidade celular $(\mathrm{P}<0,05)$ (Fig.3).

Em relação à avaliação da atividade enzimática, as cé- lulas linfocitárias incubadas com OCRA apresentaram decréscimo da atividade de E-ADA quando comparadas ao grupo controle em todos os períodos analisados $(\mathrm{P}<0.05)$, com exceção dos linfócitos incubados com as concentrações 0,001 e $1 \mu \mathrm{g} / \mathrm{mL}$ em $24 \mathrm{~h}$ de incubação (Fig.4). DON, na concentração de $0,01 \mu \mathrm{g} / \mathrm{mL}$, induziu diminuição da atividade de E-ADA em todos os tempos analisados em relação ao grupo controle $(\mathrm{P}<0,05)$ (Fig.5). Os valores da atividade de E-ADA pós-incubação com OCRA e DON estão representados nos Quadros 1 e 2, respectivamente. Os linfócitos incubados com a micotoxina ZEA não apresentaram resultados significativos (P>0,05) (Fig.6).

\section{DISCUSSÃO}

O sistema de sinalização purinérgico desempenha importante função moduladora das respostas imune e inflamatória através de moléculas extracelulares, tais como, nucleotídeos de adenina (ATP, ADP e AMP) e seus derivados nucleosídeos de Ado (Ralevic \& Burnstock 2003). Evidências indicam que altos níveis de ATP extracelular agem através de receptores específicos da superfície celular como agentes pró-inflamatórios, potencializando a liberação de citocinas pró-inflamatórias (Bours et al. 2006) a partir de linfócitos ativados (Langston et al. 2003). Entretanto, baixos níveis de ATP extracelular atuam como moduladores negativos da imunidade (Di Virgilio \& Boeynaems \& Robson 2009). A quebra de seu produto, Ado, exibe potente ação imunossupressiva e inflamatória pela inibição da proliferação de células T e secreção de citocinas (Deaglio et al. 2007, Gessi et al. 2007). Ado também age como regulador endógeno da imunidade inata, protegendo o hospedeiro de tecidos excessivamente danificados associados com inflamação intensa (Desrosiers et al. 2007). Em nosso estudo, não foi realizada a quantificação de Ado, mas sim da atividade de sua enzima extracelular E-ADA.

Uma redução na atividade de E-ADA em linfócitos levaria à interação de Ado com receptores de adenosina (AdoRs) que existem em muitos tipos celulares com possíveis efeitos anti-inflamatórios. Esta redução causaria um aumento nas concentrações extracelulares de Ado, que seria convertida em inosina. Ado atua como um sensor e fornece informação ao sistema imune através de tecidos danificados ou alterações inflamatórias agudas (Kumar \& Sharma 2009). Então, o decréscimo de E-ADA em linfócitos poderia estar relacionado a um mecanismo compensatório, o que levaria a uma elevação das concentrações extracelulares de Ado, a qual agiria sobre receptores purinérgicos, atenuando inflamação e dano tecidual, o que poderia explicar a correlação entre o aumento da viabilidade celular e a baixa atividade enzimática encontrados nos resultados associados com OCRA e DON.

Não há estudos a respeito de E-ADA em culturas de frangos de corte, mas podemos encontrar estudos semelhantes em culturas de células humanas. Iwaki-Egawa \& Watanabe (2002) demonstraram que há propriedades similares em relação às propriedades de E-ADA sobre especificidades de substrato, sensibilidades a inibidores e perfil do $\mathrm{pH}$ entre a enzima proveniente de humanos e naquela oriunda de frangos. É importante ressaltar essa informação, pois uma 
comparação entre os dados obtidos a partir de pesquisas em culturas de células humanas e os obtidos pelo presente experimento não é inválida.
0 potencial imunotóxico de OCRA tem sido estudado em diferentes modelos experimentais, consequentemente, os dados disponíveis são geralmente contraditórios e
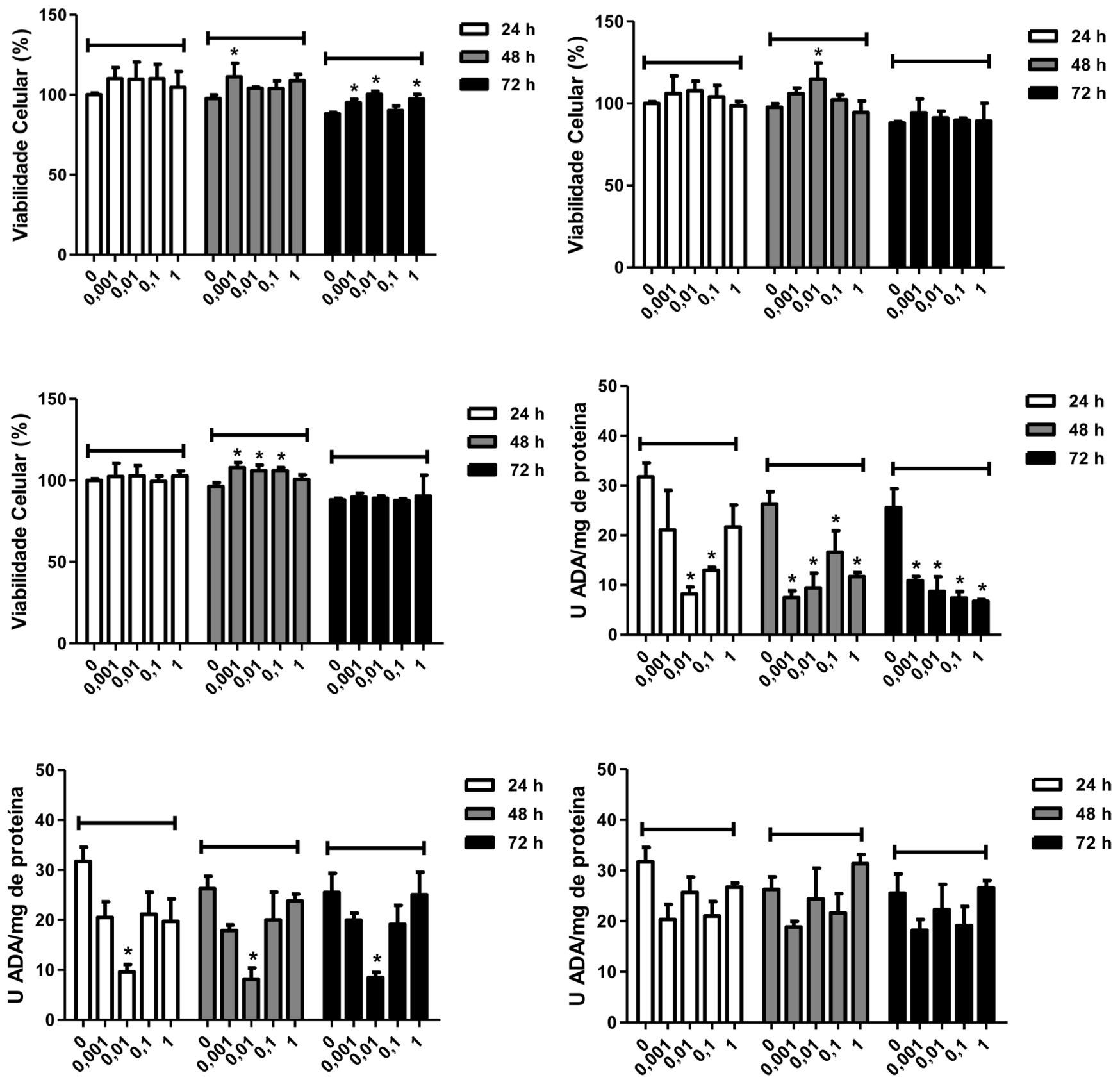

Fig.1. Viabilidade celular dos linfócitos incubados com a micotoxina OCRA nas concentrações $0 ; 0,001 ; 0,01,0,1$ e $1 \mu \mathrm{g} / \mathrm{mL}$ em 24,48 e 72 h de exposição. *Diferença significativa $(\mathrm{P}<0,05)$.

Fig.3. Viabilidade celular dos linfócitos incubados com a micotoxina ZEA nas concentrações $0 ; 0,001 ; 0,01 ; 0,1$ e $1 \mu \mathrm{g} / \mathrm{mL}$ em 24, 48 e 72 h de exposição. *Diferença significativa $(\mathrm{P}<0,05)$.

Fig.5. Atividade enzimática de E-ADA dos linfócitos incubados com a micotoxina DON nas concentrações 0; 0,001; 0,1 e 1 $1 \mu \mathrm{g} /$ $\mathrm{mL}$ em 24, 48 e $72 \mathrm{~h}$ de exposição. *Diferença significativa $(\mathrm{P}<0,05)$.

Fig.2. Viabilidade celular dos linfócitos incubados com a micotoxina DON nas concentrações $0 ; 0,001 ; 0,01 ; 0,1$ e $1 \mu \mathrm{g} / \mathrm{mL}$ em 24, 48 e 72 h de exposição. *Diferença significativa $(\mathrm{P}<0,05)$.

Fig.4. Atividade enzimática de E-ADA dos linfócitos incubados com a micotoxina OCRA nas concentrações $0 ; 0,001 ; 0,1$ e $1 \mu \mathrm{g} / \mathrm{mL}$ em 24, 48 e $72 \mathrm{~h}$ de exposição. *Diferença significativa $(\mathrm{P}<0,05)$.

Fig.6. Atividade enzimática de E-ADA dos linfócitos incubados com a micotoxina ZEA nas concentrações $0 ; 0,001 ; 0,1$ e $1 \mu \mathrm{g} /$ mL em 24, 48 e 72 h de exposição. 
Quadro 1. Atividade de E-ADA (U/mg de proteína) em linfócitos de frangos de corte incubados com as respectivas concentrações da micotoxina OCRA em 24, 48 e $72 \mathrm{~h}$ $(\mathrm{M} \pm \mathrm{SEM})$

\begin{tabular}{lccc}
\hline Concentração $(\mu \mathrm{g} / \mathrm{mL})$ & \multicolumn{3}{c}{ Período de incubação } \\
\cline { 2 - 4 } & $24 \mathrm{~h}$ & $48 \mathrm{~h}$ & $72 \mathrm{~h}$ \\
\hline 0 & $31,71^{\mathrm{a}} \pm 2,84$ & $26,25^{\mathrm{a}} \pm 2,50$ & $25,52^{\mathrm{a}} \pm 3,84$ \\
0,001 & $21,05 \pm 7,91$ & $7,45^{*} \pm 1,34$ & $10,86^{*} \pm 0,85$ \\
0,01 & $8,19^{*} \pm 1,41$ & $9,41^{*} \pm 2,93$ & $8,70^{*} \pm 2,94$ \\
0,1 & $12,95^{*} \pm 0,60$ & $16,56^{*} \pm 4,32$ & $7,34^{*} \pm 1,34$ \\
1 & $21,66 \pm 4,41$ & $11,68^{*} \pm 0,80$ & $6,74^{*} \pm 0,30$
\end{tabular}

a Grupo controle; * $(\mathrm{P}<0,05)$.

Quadro 2. Atividade de E-ADA (U/mg de proteína) em linfócitos de frangos de corte incubados com as respectivas concentrações da micotoxina DON em 24, 48 e $72 \mathrm{~h}$ $(\mathrm{M} \pm \mathrm{SEM})$

\begin{tabular}{lccc}
\hline Concentração $(\mu \mathrm{g} / \mathrm{mL})$ & \multicolumn{3}{c}{ Período de incubação } \\
\cline { 2 - 4 } & $24 \mathrm{~h}$ & $48 \mathrm{~h}$ & $72 \mathrm{~h}$ \\
\hline 0 & $31,71^{\mathrm{a}} \pm 2,84$ & $26,25^{\mathrm{a}} \pm 2,50$ & $25,52^{\mathrm{a}} \pm 3,84$ \\
0,001 & $20,53 \pm 3,12$ & $17,89 \pm 1,11$ & $19,99 \pm 1,34$ \\
0,01 & $9,61^{*} \pm 1,49$ & $8,15^{*} \pm 2,26$ & $8,48^{*} \pm 1,02$ \\
0,1 & $21,14^{*} \pm 4,41$ & $20,02 \pm 5,57$ & $19,15 \pm 3,77$ \\
1 & $19,71 \pm 4,50$ & $23,81 \pm 1,39$ & $25,05 \pm 4,51$
\end{tabular}

$\overline{{ }^{a} \text { Grupo controle; * }(\mathrm{P}<0,05)}$.

difíceis de interpretar. Essas diferentes conclusões podem ser devido às concentrações testadas da micotoxina, características particulares das linhagens celulares, diferentes condições de cultura, ao período de exposição e critérios utilizados no estudo (Alvarez-Ervitil et al. 2005). Estudos demonstram que OCRA suprime a reposta de anticorpos em inúmeras espécies (Haubeck et al. 1981, Harvey et al. 1992, Stormer \& Lea 1995, Müller et al. 1999). Em relação à imunidade humoral, OCRA induz uma regressão dose-dependente das imunoglobulinas IgG, IgA e IgM (Müller et al. 1995, Dortant et al. 2001). Em relação à imunidade mediada por células, a resposta proliferativa de células $B$ não foi alterada pela micotoxina em ratos (Dortant et al. 2001) ou camundongos (Thuvander \& Breitholtz-Emanuelsson \& Olsen 1995). A resposta proliferativa de linfócitos T apresentou decréscimo em suínos (Harvey et al. 1992) e frangos de corte (Elissalde et al. 1994). A atividade de linfócitos T citotóxicos não foi afetada em camundongos (Luster et al. 1987). Entretanto, apesar da associação de OCRA com eventos de imunossupressão, nosso estudo demonstrou que em concentrações mínimas, esta micotoxina pode induzir proliferação celular, já que a viabilidade dos linfócitos incubados com 0,001, 0,01 e $1 \mu \mathrm{g} / \mathrm{mL}$, em $72 \mathrm{~h}$ de exposição, apresentou um aumento em relação ao grupo controle.

Embora na literatura existam muitos modelos experimentais para o estudo de OCRA, poucos experimentos são desenvolvidos a partir de protocolos in vitro utilizando o isolamento de células imunes. E mais escassos ainda, são tais protocolos a partir de células imunes de frangos de corte, o que dificulta a comparação dos dados obtidos em nosso estudo. Estudos realizados com linfócitos humanos demonstraram que o tratamento com OCRA inibiu a resposta proliferativa da população de células T e a produção de IL-2 (Lea et al. 1989). OCRA também apresentou consistente efeito sobre a síntese protéica e inibição da síntese de DNA em células T (Stormer et al. 1983). Tais resultados confirmam a hipótese proposta por Creppy et al. (1983) na qual OCRA inibe a síntese protéica devido sua interação com a fenilalanina-tRNA sintetase. Mais recentemente, foi demonstrado que OCRA induz apoptose de modo dose e tempo-dependente em células T humanas através da desestabilização da função mitocondrial (Assaf et al. 2004). 0 ensaio de MTT, utilizado pelo presente estudo, para a avaliação da viabilidade linfocitária a partir da função mitocondrial, não permitiu concluir o mesmo que Assaf et al. (2004), pois em determinadas concentrações mínimas da micotoxina houve uma indução de elevação de viabilidade celular, em 48 e 72 h, mas esta não procedeu de modo dose-dependente.

Macrófagos e células T e B do sistema imune são alvos centrais de DON, que pode ser tanto imunoestimulatório quanto imunosupressivo, conforme a dose, exposição e tempo do ensaio imune funcional (Tiemann \& Dänicke 2007). Considera-se que o modo de ação primário de DON seja a habilidade de se ligar a ribossomos eucarióticos e, por consequência a isso, a inibição da síntese proteica. Mecanismos secundários, tais como bloqueio da sinalização celular, diferenciação, crescimento e síntese macromolecular também têm sido associados com exposição a DON (Costa et al. 2011). Estudos em modelos animais e linhagens celulares têm demonstrado que a exposição à DON modula a função imune por influenciar especificamente as respostas pró-inflamatórias, a distribuição das células brancas e sua proliferação em diversos órgãos (Costa et al. 2011). No estudo in vivo de Pestka (2003), baixas concentrações de DON (inferiores a $5 \mathrm{mg} / \mathrm{kg}$ de ração) pareceram estimular a imunidade e altas concentrações suprimiram a resposta imune em roedores. Em nosso estudo, a concentração $0,01 \mu \mathrm{g} / \mathrm{mL}$ foi responsável pelo aumento dos níveis de viabilidade celular em $48 \mathrm{~h}$ pós-incubação quando comparado ao grupo controle, demonstrando que DON, em concentrações mínimas, pode promover proliferação celular em avaliações in vitro a partir de culturas celulares. Infelizmente, limitadas informações são disponíveis a respeito da imunotoxicidade de DON em frangos de corte (Wageha et al. 2013), dificultando maiores discussões em relação aos dados encontrados.

Quanto à avaliação de E-ADA, DON na concentração de $0,01 \mu \mathrm{g} / \mathrm{mL}$ induziu uma reduzida atividade enzimática em todos os períodos analisados ao compararmos com o grupo controle. Estudos como o de Bach et al. (2013), Souza et al. (2012) e Tonin et al. (2012) foram utilizados para uma comparação dos resultados relacionados à atividade de E-ADA, mas a metodologia empregadas nessas pesquisas foram baseadas em pesquisas in vivo, ou seja, não houve estimulação antigênica diretamente nas células cultivas in vitro. Portanto, pode-se discutir somente o fato de que a atividade enzimática de E-ADA diminui os níveis de Ado disponíveis para estimular AdoRs expressos na superfície celular e este mecanismo contribui para a regulação do sistema imune (Hashikawa et al. 2004), sugerindo que tal mecanismo pode ter ocorrido após a incubação com 
determinadas concentrações mínimas de OCRA e DON, já que E-ADA poderia contribuir para limitar o processo de inflamação e subsequentes danos celulares (Abbracchio \& Ceruti 2007).

Pesquisas comprovam que a reduzida atividade de E-ADA também pode estar associada ao processo de hipóxia em cultivos celulares in vitro (Ramakers et al. 2012, By et al. 2012) . Apesar dessa afirmação, e sabermos que há um processo natural de decréscimo celular em cultivos in vitro, aliado ao fato de células do sistema imunológico, como os linfócitos, apresentarem sensibilidade exacerbada e manterem-se pouco tempo em cultura; ao compararmos as amostras incubadas com as diferentes concentrações das três micotoxinas testadas no presente estudo com seus grupos controles de cada período analisado, constatamos que a viabilidade celular manteve-se em níveis elevados.

Comparativamente, o estudo de Maenetje et al. (2008), cujo objetivo principal foi avaliar a citotoxicidade de $\mathrm{AFB}_{1}$, DON e OCRA sobre linfócitos isolados de humanos, utilizando também o ensaio de MTT para posterior análise da viabilidade celular, constatou que OCRA foi mais citotóxica que as outras duas micotoxinas após 24 horas de incubação. Várias hipóteses, a respeito do mecanismo de interação de OCRA e seus metabólitos com moléculas endógenas, têm sido levantadas para explicar sua toxicidade. Elas estão relacionadas a interações específicas, baseadas em ligações altamente específicas em moléculas alvos e, interações não específicas, baseadas na reatividade química de OCRA e seus metabólitos à molécula alvo (Ringot et al. 2006). Os resultados encontrados por Maenetje et al. (2008) divergem dos apresentados nesse estudo, já que as micotoxinas DON e OCRA promoveram proliferação celular, destacando-se OCRA, que ocasionou tal comportamento na maioria (exceto no grupo incubado com $0,1 \mu \mathrm{g} / \mathrm{mL}$ da micotoxina) das culturas linfocitárias incubadas com suas concentrações mínimas no período de $72 \mathrm{~h}$ de exposição, demonstrando que não houve alteração da integridade da membrana celular já que a atividade de E-ADA associada apresentou decréscimo em seus níveis.

Os dados referentes às micotoxinas OCRA e DON demonstraram que as mesmas não foram citotóxicas nas concentrações testadas, permitindo uma adequada comparação entre os parâmetros avaliados. Mas em se tratando de ZEA, que também não demonstrou citotoxicidade, esta comparação não pode ser realizada já que a mesma não induziu alteração na atividade de E-ADA. Basicamente, há dois processos de biotransformação de ZEA: primeiro, ZEA é reduzida à $\alpha$-zearalenol e $\beta$-zearalenol, reação catalisada por $3 \alpha$-HSD e $3 \beta$-HSD (enzimas hidroxiesteróide desidrogenases); segundo, ZEA e seus metabólitos reduzidos são conjugados com ácido glicurônico, transformação catalisada pela UDPGT (uridina difosfato glicuroniltransferase). Determinadas espécies animais têm susceptibilidades diferenciadas à ZEA devido seus processos de biotransformação. Conforme dados de estudos, a biotransformação hepática desta micotoxina em $\alpha$-zearalenol pode ser considerada como uma reação de bioativação e a sua transformação em $\beta$-zearalenol como uma reação de detoxificação. Em frangos, $\beta$-zearalenol é o principal produto em ambos os isola- dos de frações microssomal e pós-mitocondrial, dado consistente com estudos anteriores em hepatócitos de frangos de corte (Gajecki et al. 2010). Sendo assim, como não há biotransformação da micotoxina em $\alpha$-zearalenol pelo metabolismo hepático de frangos, consequentemente não há susceptibilidade desta espécie a contaminações por ZEA in vivo. Entretanto, in vitro, o presente estudo evidenciou aumento na viabilidade celular correspondente ao período de $48 \mathrm{~h}$ pós-incubação (exceto nas células tratadas com $1 \mu \mathrm{g} /$ $\mathrm{ml}$ da micotoxina). Este é o primeiro trabalho a demonstrar proliferação celular induzida por ZEA em linfócitos de frangos de corte. Assim como nas demais micotoxinas avaliadas em nosso estudo, ZEA também está associada a eventos de imunossupressão. Como no estudo de Vlata et al. (2006), que investigou os efeitos citopáticos in vitro de ZEA, sobre células mononucleares do sangue periférico (PBMC) isoladas de humanos em relação aos padrões de proliferação e morte celular de células não tratadas e mitógeno-ativadas, constatando que em concentrações superiores a $30 \mu \mathrm{g} /$ $\mathrm{mL}$, ZEA inibiu totalmente a proliferação de linfócitos T e $\mathrm{B}$, e seus efeitos inibitórios foram relacionados à necrose $\mathrm{e}$ apoptose celular.

É importante destacar que este é o primeiro estudo realizado com OCRA, DON e ZEA, em linfócitos de frangos de corte cultivados in vitro, a avaliar sua citotoxicidade a partir dos parâmetros de viabilidade celular e atividade de E-ADA.

\section{CONCLUSÕES}

Os ensaios colorimétricos utilizados para avaliação de viabilidade celular e atividade enzimática permitiram adequada comparabilidade dos resultados entre as diferentes micotoxinas.

Foi possível correlacionar a proliferação celular ocasionada por determinadas concentrações de OCRA e DON com um decréscimo da atividade de E-ADA em linfócitos de frangos de corte incubados com as respectivas micotoxinas.

Tais evidências sugerem que em concentrações mínimas as micotoxinas testadas não estimularam a atividade da enzima, que possui ação pró-inflamatória e contribui para o processo de imunossupressão e, portanto, evitando um decréscimo na viabilidade celular.

Para afirmar que as concentrações mínimas testadas, além de induzirem proliferação, induzem imunoestímulo são necessários maiores estudos, bem como o uso de técnicas com maior especificidade como a quantificação de citocinas envolvidas na imunomodulação.

Este é o primeiro trabalho a demonstrar proliferação celular induzida por ZEA em linfócitos de frangos de corte.

\section{REFERÊNCIAS}

Abbracchio M.P. \& Ceruti S. 2007. P1 receptors and cytokine secretion. Purinergic Signal. 3:315-325.

Alvarez-Ervitil L., Leache C., Gonzallez-Peflas E. \& Lopez C.A. 2005. Alterations induced in vitro by ochratoxin A in rat lymphoid cells. Hum. Exp. Toxicol. 24:459-466.

Assaf H., Azouri H. \& Pallardy M. 2004. Ochratoxin A induces apoptosis in human lymphocytes through down regulation of BCI-XL. Toxicol. Sci. 79:335-344 
Bach B.C., Leal D.B.R., Jaques J.A.S., Souza V.C.G., Ruchel J.B., Schlemmer K.B., Zanette R.A., Hecktheuer P.A., Pereira P.L., Casali E.A., Alves S.H. \& Santurio J.M. 2013. E-ADA activity in lymphocytes of an experimental model of pythiosis treated with immunotherapy. Cell Biochem. Funct. 31:476-481.

Bours M.J., Swennen E.L., Di Virgilio F., Cronstein B.N. \& Dagnelie P.C. 2006. Adenosine 5'-triphosphate and adenosine as endogenous signaling molecules in immunity and inflammation. Pharmacol. Therapeut. 112:358404.

Böyum A. 1968. Isolation of mononuclear cells and granulocytes from human blood. Isolation of mononuclear cells by one centrifugation, and of granulocytes by combining centrifugation and sedimentation at $1 \mathrm{~g}$. Scand. J. Clin. Lab. Invest. Suppl. 97:77-89.

Bradford M.M. 1976. A rapid and sensitive method for the quantification of microgram quantities of protein utilizing the principle of protein-dye binding. Anal. Biochem. 72:248-254.

By Y., Jacquin L., Franceschi F., Durand-Gorde J.M., Condo J., Michelet P., Guieu R. \& Ruf J. 2012. Fall in oxygen tension of culture medium stimulates the adenosinergic signalling of a human $\mathrm{T}$ cell line. Purinergic Signal. 8:661-667.

Chen F., Ma Y., Xue C., Ma J., Xie Q., Wang G., Bi Y. \& Cao Y. 2008. The combination of deoxynivalenol and zearalenone at permitted feed concentrations causes serious physiological effects in young pigs. J. Vet. Sci. 9(1):39-44.

Codero O., Salgado F., Fernández-Alonso C., Herrera C., Lluis C., Franco R. \& Nogueira M. 2001. Cytokines regulate membrane adenosine deaminase on human activated lymphocytes. J. Leukoc. Biol. 70:920-930.

Costa A.N., Keen J.N., Wild C.P. \& Findlay J.B.C. 2011. An analysis of the phosphoproteome of immune cell lines exposed to the immunomodulatory mycotoxin deoxynivalenol. Biochim. Biophys. Acta 1814:850-857.

Creppy E.E., Kern D., Steyn P.S., Vleggaar R., Röschenthaler R. \& Dirheimer G. 1983. Comparative study of the effect of ochratoxin A analogues on yeast aminoacyl-tRNA synthetases and on the growth and protein synthesis of hepatoma cells. Toxicol. Lett. 19:217-224.

Deaglio S., Dwyer K.M., Gao W., Friedman D., Usheva A., Erat A., Chen J.F., Enjyoji K., Linden J., Oukka M., Kuchroo V.K., Strom T.B. \& Robson S.C. 2007. Adenosine generation catalyzed by CD39 and CD37 expressed on regulatory T cells mediates immune suppression. J. Exp. Med. 204:1257-1265.

Desrosiers M.D., Katherine M.C., Fakir M.J., Stephens L.A., Jama F.M., Shameli A., Mehal W.Z., Santamaria P. \& Shi Y. 2007. Adenosine deamination sustains dendritic cell activation in inflammation. J. Immunol. 179:1884-1892.

Di Virgilio F., Boeynaems J.M. \& Robson S.C. 2009. Extracellular nucleotides as negative modulators of immunity. Curr. Opin. Pharmacol. 9:507513.

Dortant P.M., Peters-Volleberg G.W.M., Van Loveren H., Marquardt R.R. \& Speijers G.J.A. 2001. Age-related differences in the toxicity of ochratoxin A in female rats. Food. Chem. Toxicol. 39:55-65.

Elissalde M.H., Ziprin R.L., Huff W.E., Kubena L.F. \& Harvey R.B. 1994. Effects of ochratoxin A on Salmonella-challenged broiler chicks. Poult. Sci. 73:1241-1248.

Franco R., Casado V., Ciruela F., Saura C., Mallo J., Canela E.I. \& Llouis C. 1997. Cell surface adenosine deaminase: much more than an ectoenzyme. Prog. Neurobiol 52:283-294.

Gajęcki M., Gajęcka M., Jakimiuk E., Zielonka Ł. \& Obremski K. 2010. Zearalenone biotransformation, p.137-138. In: Raí M. \& Varma A. (Eds), Mycotoxins in Food, Feed and Bioweapons. Cap.9. Springer, Heidelberg. 405p.

Gessi S., Varani K., Merighi S., Fogli E., Sacchetto V., Benini A., Leung E., Mac-Lennan S. \& Borea P.A. 2007. Adenosine and lymphocyte regulation. Purinergic Signal. 3:109-116.

Giusti G. \& Galanti B. 1984. Methods of Enzymatic Analysis. Verlag Chemie, Weinheim, p.315-323.

Goyarts T., Dänicke S., Brüssow K.P., Valenta H., Ueberschär K.H. \& Tiemann U. 2007. On the transfer of the Fusarium toxins deoxynivalenol (DON) and zearalenone (ZON) from sows to their fetuses during days 35-70 of gestation. Toxicol. Lett. 171:38-49.
Harvey R.B., Elissalde M.H., Kubena L.F., Weaver E.A., Corrier D.E. \& Clement B.A. 1992. Immunotoxicity of ochratoxin A to growing gilts. Am. J. Vet. Res. 53:1966-1970.

Hashikawa T., Hooker S.W., Maj J.G., Knott-Craig C.J., Takedachi M., Murakami S. \& Thompson L.F. 2004. Regulation of adenosine receptor engagement by ecto-adenosine deaminase. FASEB J. 18:131-133.

Haubeck H.D., Lorkowski G., Kölsch E. \& Röschthaler R. 1981. Immunosuppression by ochratoxin A and its prevention by phenylalanine. Appl. Environ. Microbiol. 41:1040-1042.

Iwaki-Egawa S. \& Watanabe Y. 2002. Characterization and purification of adenosine deaminase 1 from human and chicken liver. Comp. Biochem. Phys. B. 133:173-182.

Kumar V. \& Sharma A. 2009. Adenosine: an endogenous modulator of innate immune system with therapeutic potential. Eur. J. Pharmacol. 616:7-15.

Langston H.P., Ke Y., Gewirtz A.T., Dombrowski K.E. \& Kapp J.A. 2003. Secretion of IL-2 and IFN- $\gamma$, but not IL-4, by antigen-specific T cells requires extracellular ATP. J. Immunol. 170:2962-2970.

Lea T., Steien K. \& Stormer F.C. 1989. Mechanism of ochratoxin A-induced immunosuppression. Mycopathologia 107:153-159.

Lewis C.W., Smith J.E., Anderson J.G. \& Freshney R.I. 1999. Increased cytotoxicity of food-borne mycotoxins toward human cell lines in vitro enhaced cytochrome p450 expression using the MTT bioassay. Mycopathologia 148:97-102.

Luster M.I., Germolec D.R., Burleson G.R., Jameson C.W., Ackermann M.F., Lamm K.R. \& Hayes H.T. 1987. Selective immunosuppression in mice of natural killer cell activity by ochratoxin A. Cancer Res. 47:2259-2263.

Maenetje P.W., Villiers N. \& Dutton M.F. 2008. The use of isolated human lymphocytes in mycotoxin cytotoxicity testing. Int. J. Mol. Sci. 9:1515-1526.

Müller G., Kielstein H., Kohler H., Berndt A. \& Rosner H. 1995. Studies of the influence of ochratoxin $A$ on immune and defence reactions in the mouse model. Mycoses 38:85-91.

Pestka J.J. 2003. Deoxynivalenol-induced IgA production and IgA nephropathy-aberrant mucosal immune response with systemic repercussions. Toxicol. Lett. 140:287-295.

Ralevic V. \& Burnstock G. 2003. Involvement of purinergic signaling in cardiovascular diseases. Drug News Perspect. 16:133-140.

Ramakers B.P., Wever K.E., Kox M., Broek P.H., Mbuyi F., Rongen G., Masereeuw R., Hoeven J.G., Smits P., Riksen N.P. \& Pickkers P. 2012. How systemic inflammation modulates adenosine metabolism and adenosine receptor expression in humans in vivo. Crit. Care Med. 40(9):2609-2616.

Ringot D., Chango A., Schneider Y.J. \& Larondelle Y. 2006. Toxicokinetics and toxicodynamics of ochratoxin A, an update. Chem. Biol. Interact. 159:18-46.

Santurio J.M. 2000. Micotoxinas e micotoxicoses na avicultura. Revta Bras. Ciênc. Avic. 2(1):1-12.

Souza V.C.G., Schlemmer K.B., Noal C.B., Jaques J.A.S., Zimmermann C.E.P., Leal C.A.M., Fleck J., Casali E.A., Morsch V.M., Schetinger M.R.C. \& Leal D.B.R. 2012. E-NTPDase and E-ADA activities are altered in lymphocytes of patients with indeterminate form of Chagas' disease. Parasitol. Int. 61:690-696.

Stormer F.C. \& Lea T. 1995. Effects of ochratoxin A upon early and late events in human T-cell proliferation. Toxicology 95:45-50.

Stormer F.C., Storen O., Hansen C.E., Pedersen J.I. \& Aasen A.J. 1983. Formation of (4R)-and (4S)-4-hydroxyochratoxin A and 10-hydroxyochratoxin A from ochratoxin A by rabbit liver microsomes. Appl. Environ. Microbiol. 45:1183-1187.

Thuvander A., Breitholtz-Emanuelsson A. \& Olsen M. 1995. Effects of ochratoxin A on the mouse immune system after subchronic exposure. Food Chem. Toxicol. 33:1005-1011.

Tiemann U. \& Dänicke S. 2007. In vivo and in vitro effects of the mycotoxins zearalenone and deoxynivalenol on different non-reproductive and reproductive organs in female pigs: A review. Food Addit. Contam. A 24(3):306-314.

Tonin A.A., Pimentel V.C., Silva A.S., Azevedo M.I., Souza V.C.G., Wolkmer P., 
Rezer J.F.P., Badke M.R.T., Leal D.B.R., Schetinger M.R.C., Monteiro S.G. \& Lopes S.T.A. 2012. Adenosine deaminase activity in serum, erythrocytes and lymphocytes of rats infected with Leptospira icterohaemorrhagiae. Res. Vet. Sci. 92:197-201.

Vlata Z., Porichis F., Tzanakakis G., Tsatsakis A. \& Krambovitis E. 2006. A study of zearalenone cytotoxicity on human peripheral blood mononuclear cells. Toxicol. Lett. 165:274-281.

Wageha A., Ghareeb K., Böhm J. \& Zentek J. 2013. The toxicological impacts of the Fusarium mycotoxin, deoxynivalenol, in poultry flocks with special reference to immunotoxicity. Toxins 5:912-925.

Wang G.H., Xue C.Y., Chen F., Ma Y.L., Zhang X.B., Bi Y.Z. \& Cao Y.C. 2009. Effects of combinations of ochratoxin $\mathrm{A}$ and $\mathrm{T}-2$ toxin on immune function of yellow-feathered broiler chickens. Poult. Sci. 88:504-510.

Widestrand J., Lundh T., Pettersson H. \& Lindberg J.E. 1999. Cytotoxicity of four trichothecenes evaluated by three colorimetric bioassays. Mycopathologia 147:149-155. 